\title{
NASA's Space Launch System: Launch Capability for Lunar Exploration and Transformative Science
}

\author{
Stephen D. Creech \\ NASA Space Launch System Program \\ Mailstop XP50, Marshall Space Flight Center, AL 35812 \\ Steve.creech@nasa.gov
}

\begin{abstract}
Excitement is building for the first launch of NASA's Space Launch System (SLS), a unique exploration asset for the agency's Artemis lunar program as well as for a new generation of science missions. SLS is designed for an array of missions beyond Earth's orbit. The flexible system, which can be configured for Orion, cargo or Orion with comanifested payload missions, offers high escape velocities to send more mass to deep space destinations. When configured with an $8.4 \mathrm{~m}$-diameter fairing, SLS offers unmatched payload volume for human exploration and science missions. The initial Block 1 variant will insert at least 26 metric tons (t) to translunar injection (TLI) and the more powerful Block $1 \mathrm{~B}$ vehicle will launch 34-37 t to TLI using a new-development upper stage. Much of the initial SLS Block 1 vehicle is complete, including the upper stage and payload section, the core stage, engines and the solid rocket boosters. The first mission, Artemis I, launching from modernized and upgraded facilities at Kennedy Space Center (KSC), will be an uncrewed test flight of SLS, Orion and ground processing, with a primary objective of testing Orion's heat shield at lunar re-entry velocity. Artemis I will have accommodations for $136 \mathrm{U}$ CubeSat payloads. These CubeSat missions will be deployed along the upper stage disposal trajectory after Orion separates from the vehicle. A rare opportunity for CubeSats to be deployed beyond low Earth orbit (LEO), Artemis I CubeSat missions range from searching for hydrogen and other volatiles on the lunar South Pole to studying the acceleration mechanisms of solar and interplanetary particles from a heliocentric trajectory. With manufacturing of the initial vehicle complete, fabrication and procurement is progressing for the second flight of SLS and Orion, Artemis II. Also an SLS Block 1 and Orion flight launching from KSC, Artemis II will mark the return of American astronauts to deep space with a lunar flyby-free return trajectory mission. With the Artemis III flight, NASA has the goal to land the first woman and the next man on the Moon. Infrastructure beyond SLS will be required for this effort, including elements of the lunar Gateway as well as lunar rovers, landers and additional commercially supplied launch services. SLS, as the only vehicle with the capability to lift $26 \mathrm{t}$ of mass to TLI in its initial Block 1 variant, will remain a key component of this new-era exploration program. Future variants - Block 1B and Block 2 - will lift 34-45 $t$ to TLI. This paper will discuss the status of testing and integration for the Artemis I vehicle, manufacturing progress for the second vehicle and the manifest outlook for primary, co-manifested and secondary payloads in the current deep space exploration environment.
\end{abstract}

\section{TABLE OF CONTENTS}

1. INTRODUCTION ..........................................................1

2. Progressively More PoWerful Vehicles ...2

3. PATH TO FLIGHT..........................................................3

4. FUTURE CAPABILITIES ...............................................8

5. SLS FOR SCIENCE MISSIONS.....................................9

6. CONCLUSION .............................................................12

7. REFERENCES ..............................................................13

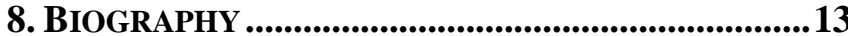

\section{INTRODUCTION}

With strong bipartisan support from Congress and the U. S. administration, NASA is focused on returning its human spaceflight program to deep space. Pursuing an ambitious goal to return astronauts to the lunar surface in 2024, NASA has named its efforts to return to the Moon after the twin sister of Apollo and goddess of the Moon in Greek mythology: Artemis.

As a critical enabling capability for the Artemis program, the Space Launch System (SLS) super heavy-lift rocket will launch the Orion crew vehicle to lunar orbit. Available in crew and cargo configurations and with progressively more powerful variants scheduled to come online in the 2020s, SLS can also be used to launch large-volume infrastructure to the Moon and eventually to Mars.

Beyond the Artemis program, SLS can be configured with $8.4 \mathrm{~m}$-diameter fairings to make a new generation of science missions possible. Engineers are also studying even larger fairings, $10 \mathrm{~m}$ in diameter, to provide enough volume for a wide array of transformative science missions and deployment of infrastructure to Mars. Providing highly energetic launches and more mass to destination, SLS can reduce cruise times or enable more robust payloads to the outer solar system. 


\section{Progressively More Powerful VEHICLES}

SLS incorporates a proven propulsion system that leverages space shuttle systems but is upgraded for improved performance and to operate at SLS's more extreme requirements and environments. Twin solid rocket boosters generate more than 75 percent of thrust at liftoff. The boosters' maximum average thrust is more than 7 million pounds. Four RS-25 liquid hydrogen (LH2)/liquid oxygen (LOX)-fed engines generate more than 500,000 lbs. of thrust each. Total liftoff thrust for the SLS vehicle is more 8.8 million pounds. The Block 1 vehicle's upper stage, the Interim Cryogenic Propulsion Stage (ICPS), a modified Delta IV Heavy stage built by Boeing and United Launch Alliance (ULA), enables the vehicle to achieve a mass to TLI of at least 26 metric tons (t). Block 1 has volume for CubeSat payloads around the circumference of the Orion Stage Adapter (OSA), which connects the ICPS to Orion's spacecraft adapter (see Section 3). In its cargo configuration, the Block 1 vehicle can accommodate a $5 \mathrm{~m}$ cargo fairing, providing $229 \mathrm{~m}^{3}$ of volume for payloads (see Figure 16).

Block 1B will be the next major variant to come online and will replace the ICPS with a more powerful upper stage: the Exploration Upper Stage (EUS). The four-engine LH2/LOX EUS will improve mass to TLI performance to 34-37 t, depending on crew or cargo configuration. The crew

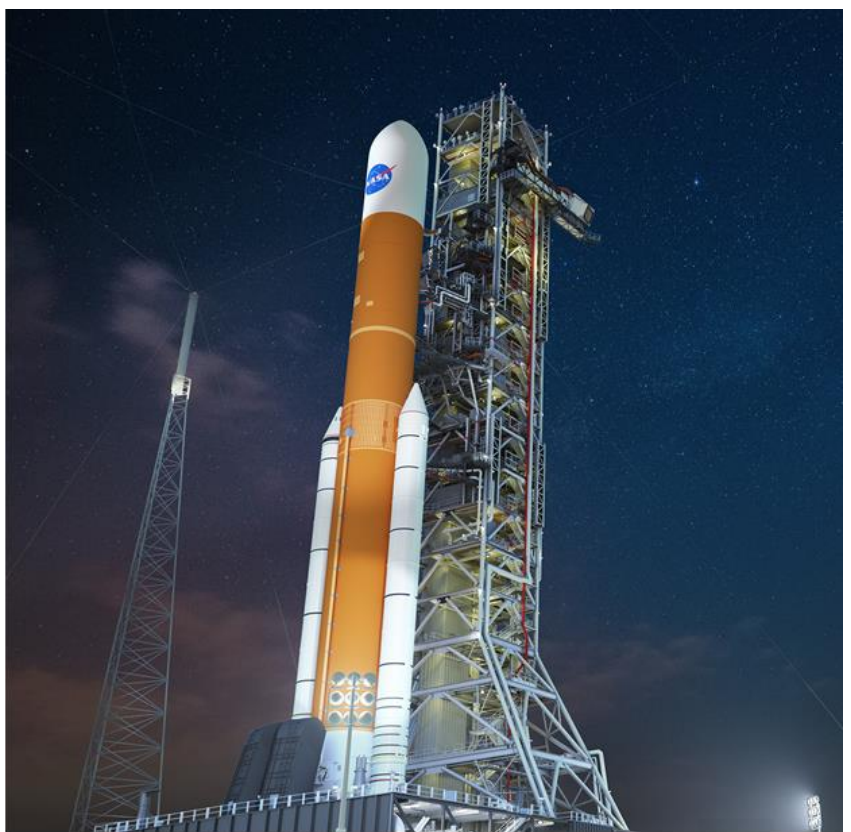

Figure 1. Artist's rendering of the Space Launch System (SLS) Block 1B with an $8.4 \mathrm{~m}$-diameter fairing on the Mobile Launcher (ML) at Launch Complex 39B at NASA's Kennedy Space Center (KSC)

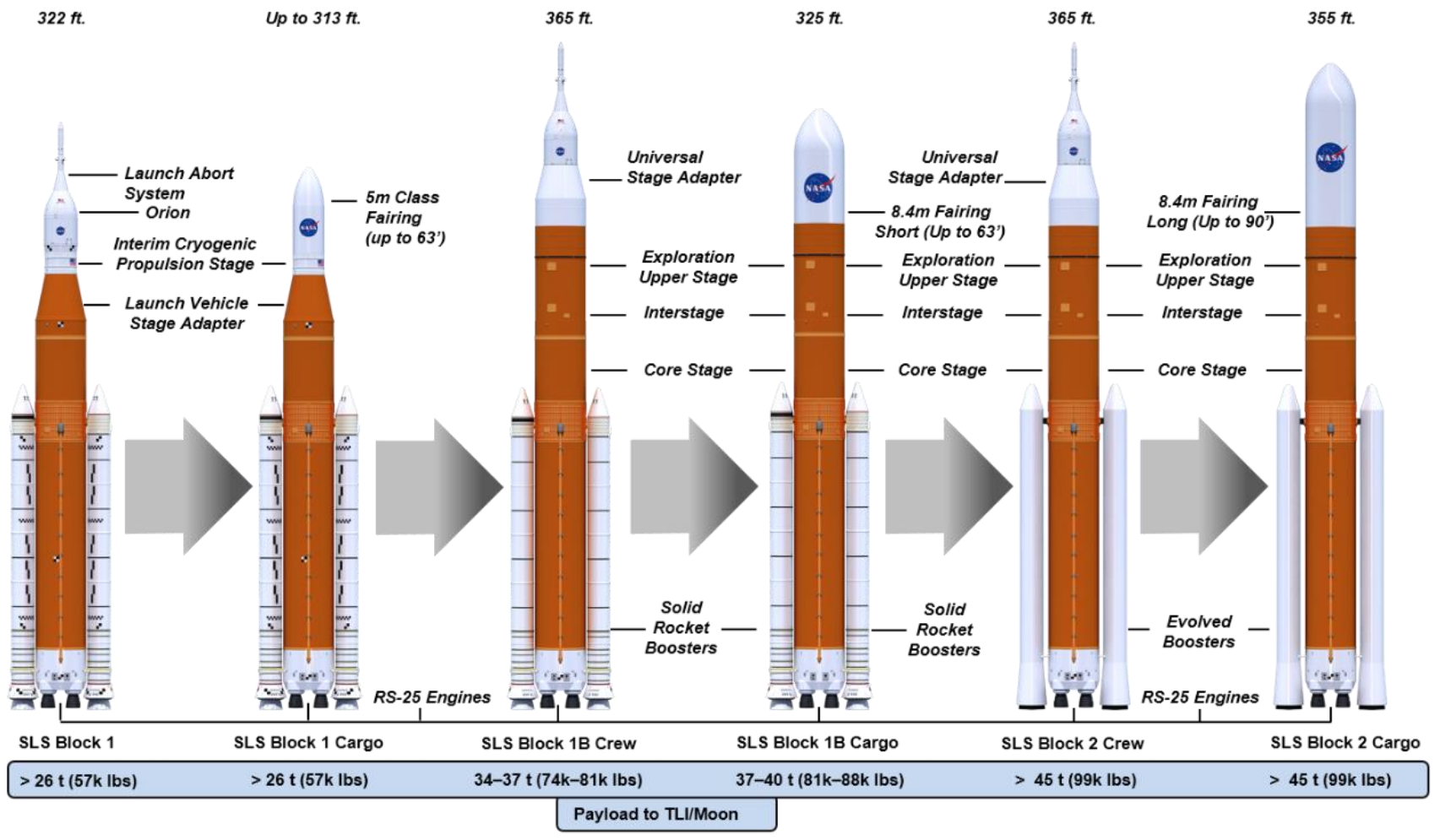

Figure 2. SLS will evolve to progressively more powerful variants, offering more mass to destination and volume for payloads than commercial vehicles provide 
configuration has $286 \mathrm{~m}^{3}$ of volume available in the Universal Stage Adapter (USA) for a co-manifested payload to ride along with crewed launches. Co-manifested payloads can be up to $10 \mathrm{t}$. In its cargo configuration, the Block 1B vehicle can be outfitted with an 8.4 m-diameter cargo shroud to provide unprecedented volume for science missions. Two lengths of $8.4 \mathrm{~m}$-diameter fairings are being evaluated: The $19.1 \mathrm{~m}$ fairing provides $621 \mathrm{~m}^{3}$ of volume while the $27.4 \mathrm{~m}$ fairing provides $988 \mathrm{~m}^{3}$ (see Figure 16). Fairings $10 \mathrm{~m}$ in diameter (also $19.1 \mathrm{~m}$ and $27.4 \mathrm{~m}$ long) are also being evaluated.

With the first Block 1 vehicle entering final testing and completed elements moving to Kennedy Space Center (KSC) in 2020, work is progressing on the second Block 1 crew vehicle, designated for the Artemis II mission that will see the return of NASA astronauts to cislunar space for the first time since Apollo 17. With many of the challenges of first-time manufacturing and assembly resolved, the program anticipates an eventual flight rate of one mission per year, commensurate with appropriations.

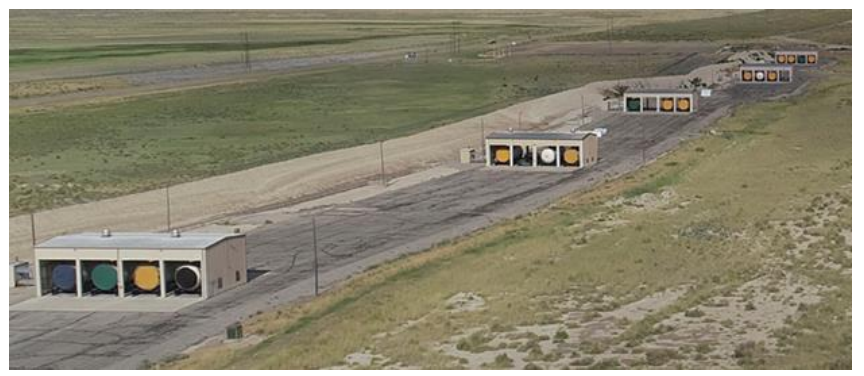

\section{Figure 3. Solid rocket boosters prime contractor Northrop Grumman has completed the motor segments for the first two Artemis flights}

\section{Path to Flight}

NASA's SLS vehicle is designed for deep space exploration missions and to give NASA guaranteed access to deep space. Accommodating both crew and science payloads, SLS is a flexible system, configurable to enable crew, crew with co-manifested payload and cargo-only missions. SLS will evolve through block upgrades to progressively more powerful variants. A proven propulsion system and a core stage are common elements to all planned variants - Blocks $1,1 \mathrm{~B}$ and 2 . The initial vehicle to fly, Block 1 in the crew configuration, has entered final testing and will fly a test mission known as Artemis I (formerly Exploration Mission1) in preparation for the return of crewed flights to cislunar space.

\section{Solid Rocket Boosters}

The solid rocket boosters for Artemis I are nearly complete (see Figure 3). The five-segment motors have an extra propellant segment compared to space shuttle motors. The SLS boosters also feature new asbestos-free insulation and new avionics. The motor cases, nose cones, frustums, forward skirts and aft skirts remain from the shuttle program and have been refurbished for SLS missions. Prime contractor Northrop Grumann has completed the motors for the Artemis I flight at its facilities in Utah, while the forward and aft assemblies are in final processing at KSC. The motor segments are scheduled to be delivered to the Exploration Ground Systems (EGS) program, which has responsibility for integrating and launching the SLS/Orion stack, in 2020. The forward and aft assemblies are also scheduled for delivery in 2020 .

For the Artemis II flight, Northrop Grumman has also completed all 10 motor segments. Recently, the aft exit cones, part of the nozzle assemblies, were completed for the second flight set. At KSC, Northrop Grumman technicians have begun work on refurbishing the forward assemblies and aft skirts for the second flight. Frustums have been gritblasted to prepare for the refurbishment, non-destructive evaluation (NDE) and paint application. The first Artemis II aft skirt to begin processing, the left hand aft skirt, has been through grit blasting operations, NDE, kick ring painting

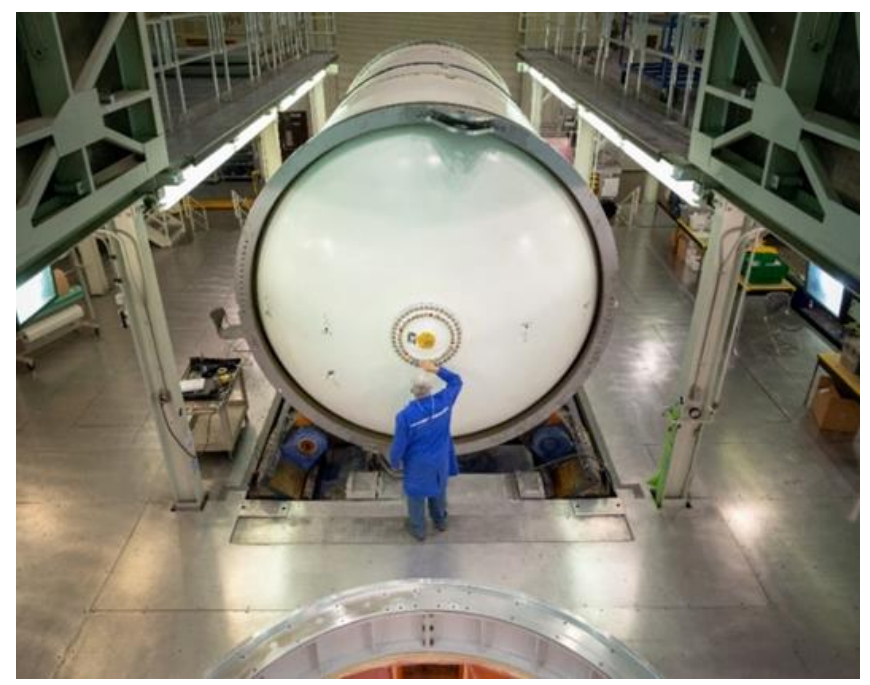

Figure 4. Completed booster motor segment for the second SLS flight, Artemis II

and preparation for the Thrust Vector Control (TVC) subframe fit check. Beyond Artemis II, booster processing is also in progress for the third flight set.

\section{RS-25 Main Engines}

The SLS Program began with 16 engines from the shuttle program, including two unflown engines, to support the first four SLS flights. The flight-proven engines will operate at 109 percent of original rated thrust versus 104.5 percent used during shuttle launches. The RS-25 engines for SLS flights have been upgraded with new controllers and additional insulation. The ability to use the RS-25 engine for SLS was validated by a series of hot-fire tests using RS-25 development engines to ensure the space shuttle-heritage 
engine can operate to the different SLS requirements and environments, such as a different propellant inlet temperature, start process and thrust profile. The hot-fire tests at Stennis Space Center (SSC) also validated new engine controllers and software. So far, 32 tests have amassed nearly 15,000 seconds of hot-fire time. Testing included running an RS-25 at 113 percent of its original designed thrust to show it can operate safely at the planned 111 percent.

The four Artemis I engines have been installed in the core stage at NASA's Michoud Assembly Facility, near New Orleans. Michoud is NASA's rocket manufacturing complex, where the first stages of the Apollo-era Saturn I, IB and V vehicles were manufactured, as well as the space shuttle external tank. For SLS, Michoud has been upgraded and modernized with installation of the world's largest spacecraft welding tool, the Vertical Assembly Center (VAC). For Artemis II, all controllers have been hot-fire tested at SSC and two engines are complete and stored in place at SSC. The remaining two flight engines are being processed by prime contractor Aerojet Rocketdyne at SSC.

To supply engines beyond the fourth flight, the SLS Program has contracted with Aerojet Rocketdyne to restart production of $\mathrm{RS}-25 \mathrm{~s}$ using modern manufacturing techniques and innovations such as additive manufacturing. These efforts are reducing touch labor, parts, welds and other processes to lower costs by at least 30 percent. Testing has included developmental components such as an additively manufactured pogo accumulator and a hot isostatic pressure (HIP)-bonded main combustion chamber for eight new-build RS-25 engines for development and flight. Engine testing resumes in 2020 and will include green run tests of additional controllers for future engines.

In addition to its work on the RS-25s, Aerojet Rocketdyne has also completed six RL10 engines to be used in the ICPS and future EUS upper stages (see Figure 13).

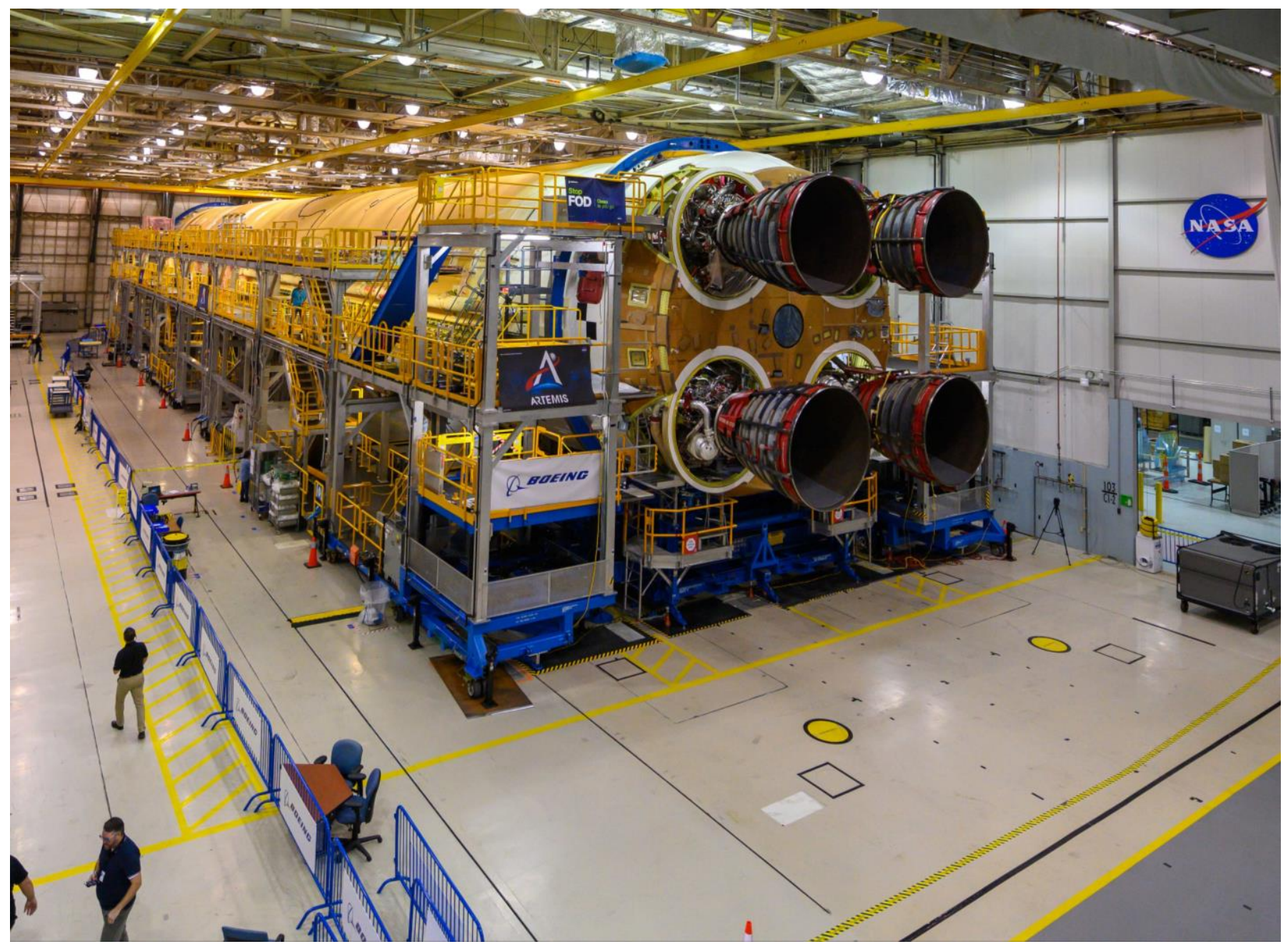

Figure 5. The SLS Program's major new development, the core stage, was completed in late 2019 and will ship to SSC for Green Run testing in 2020. 
The SLS core stage measures more than $64 \mathrm{~m}$ and consists of a forward skirt, where flight computers are located; the LOX tank; an intertank structure; the LH2 tank and the engine section and boattail assembly (see Figure 5). The core stage for Artemis I is fully constructed; the components have been joined and the engines were installed in the final months of 2019. Prime contractor Boeing manufactured the core stage using the VAC and other advanced welding tools at Michoud. The LH2 tank stands more than $39.5 \mathrm{~m}$ tall and holds up to 2 million liters of $\mathrm{LH} 2$ cooled to $-252^{\circ} \mathrm{C}$; the LOX tank holds 742,000 liters of oxidizer. Welding the thick walls of the barrels and rings that comprise the LOX tank pushed the boundaries of the state of the art in selfreacting friction-stir welding. The engine section also proved challenging and complex, with numerous feedlines, cables and other subsystems to connect. Attach points for the solid rocket boosters are located on the engine section and the intertank.

After final work on connections and checkout testing, the stage will ship to SSC for a "Green Run" test campaign. NASA's barge Pegasus will transport the enormous stage from Michoud to SSC, where the B-2 test stand has been upgraded, activated and is ready for the stage. Pegasus was lengthened and reinforced to transport the SLS core stage. Crews removed a $35 \mathrm{~m}$ section of the barge and replaced it with a $50 \mathrm{~m}$ section specially designed to increase the weight Pegasus can ferry. Length of the barge increased from $79 \mathrm{~m}$ to $94 \mathrm{~m}$.

The program chose to manufacture a core stage pathfinder, a steel structure designed to simulate the weight, center of gravity and outer mold line of the flight article. The core stage pathfinder has proven valuable for giving transportation and logistics crews experience handling fullscale equipment, including performing lifts using overhead cranes, before flight hardware arrives. Crews at Michoud used the core stage pathfinder to perform a variety of lifts, maneuvers and transportation moves. Technicians then loaded the pathfinder onto Pegasus, which transported it to SSC. Crews at NASA's rocket engine test facility unloaded the pathfinder and lifted it vertically into the B-2 test stand, paving the way for the flight article. Pegasus then delivered the core stage pathfinder to KSC, where crews offloaded it and delivered it to the Vehicle Assembly Building (VAB). More lifts, including a practice maneuver over the transfer aisle, have been completed. Pegasus then returned the core stage pathfinder to Michoud.

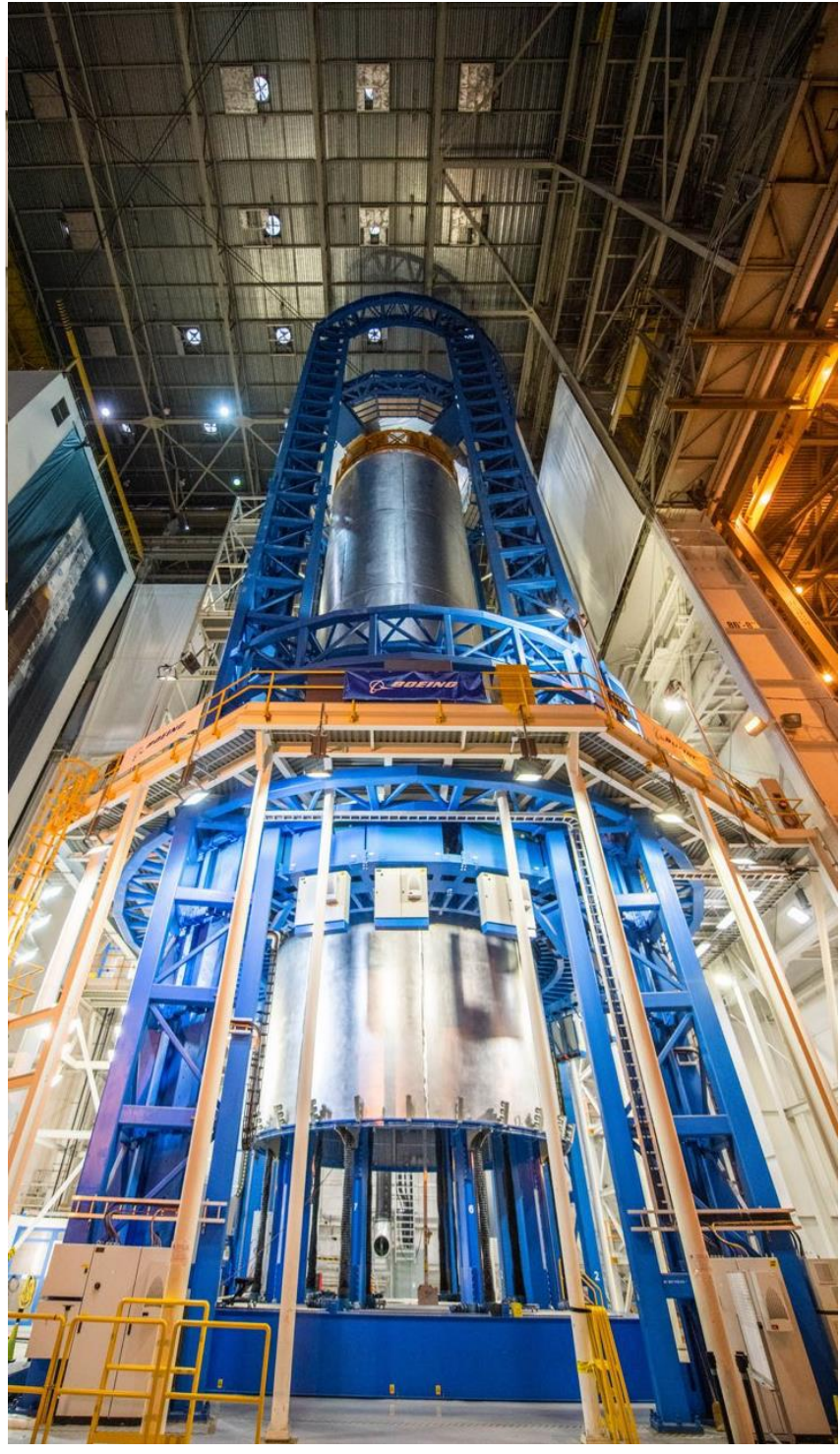

Figure 6. Welding the Artemis II liquid hydrogen (LH2) tank on the Vertical Assembly Center (VAC)

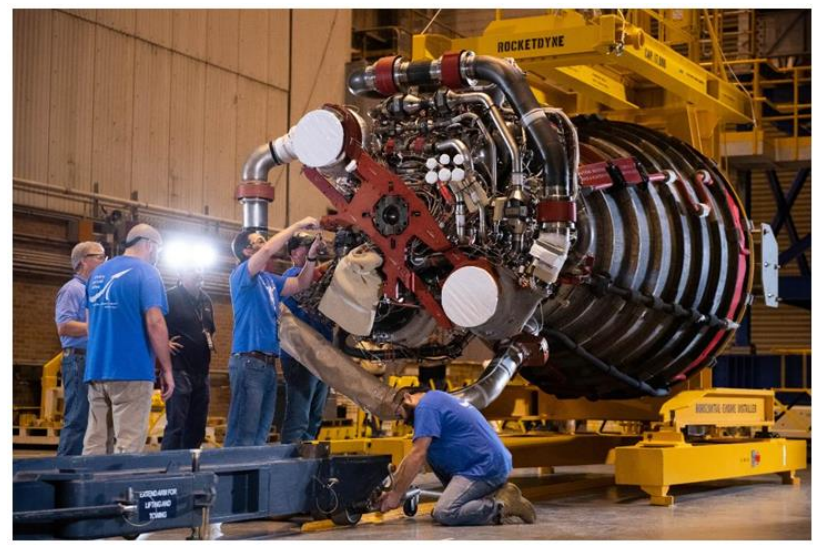

Figure 7. The first RS-25 beginning installation into the Artemis I core stage 


\section{Green Run}

The Green Run test series will include a number of "firsts" for both SLS and NASA. Green Run will be the first time the SLS propellant tanks are filled; the first end-to-end flow test of propellants and other fluids through the complete stage; the first operational test of stage avionics; and the provide three burns during the Artemis I mission: the perigee raise maneuver, the TLI burn and a disposal burn to put the stage in a heliocentric trajectory. Built by ULA and Boeing, the Delta Cryogenic Second Stage (DCSS) required some modifications for SLS's Artemis I flight: the LH2 tank was lengthened, hydrazine bottles for attitude control were

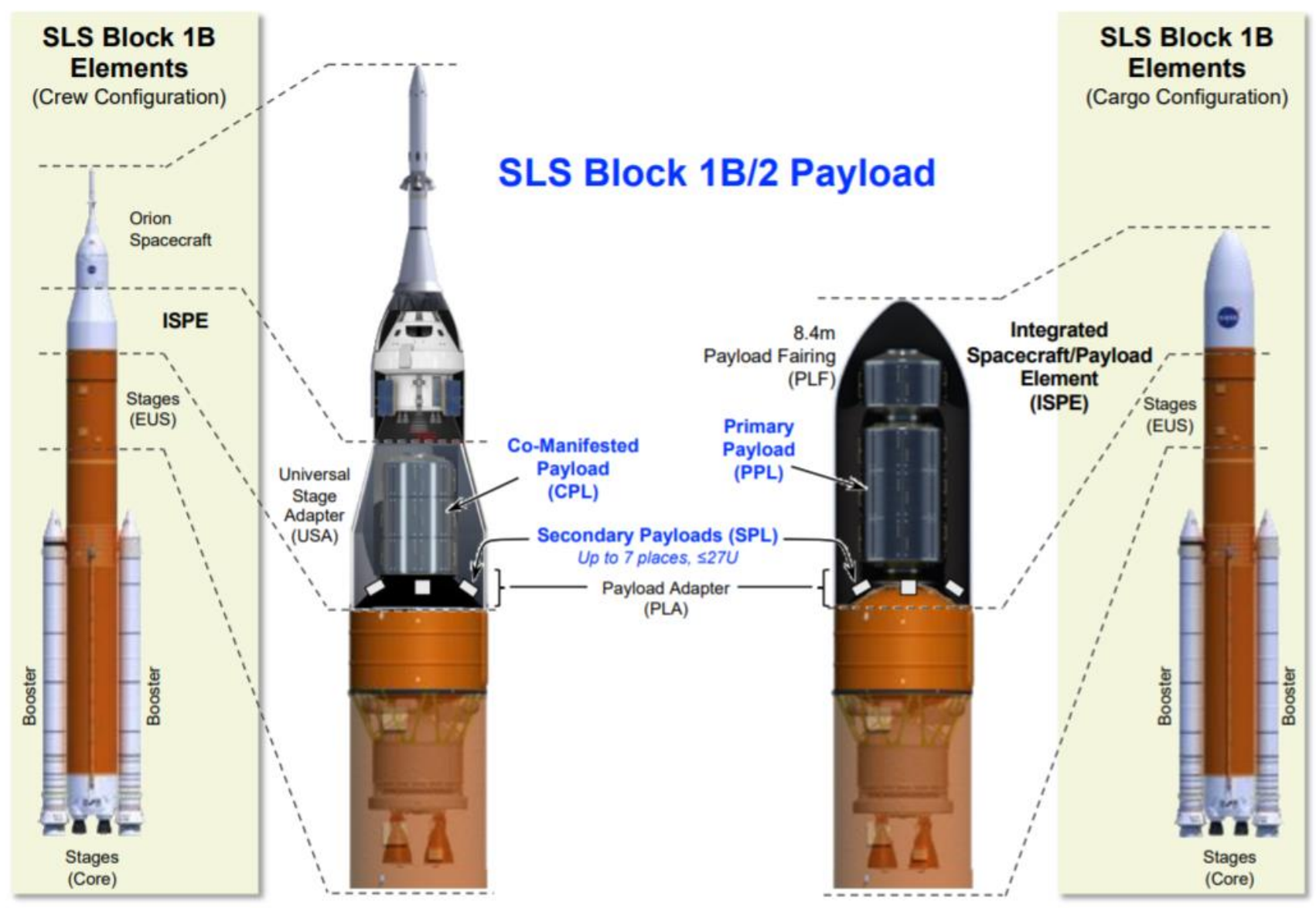

Figure 8. Payload accommodations in SLS Block 1B and 2 crew and cargo configurations

first time the four RS-25 engines are fired simultaneously. Length of the four-engine hot-fire test is currently under review. As currently baselined, Green Run includes both qualification and acceptance testing. The test campaign will validate the core stage design, design models and workmanship and verify the stage is ready to ship to KSC for final processing and integration. In addition to the hotfire testing, the entire test program as currently outlined involves a number of prerequisite tests, including vibration testing, power-on, leak and functional checks, hydraulics and TVC, safing, simulated countdown and "wet dress rehearsal" during which propellants are flowed through the stage but not ignited.

\section{Upper Stage and Adapters}

The ICPS for Artemis I was completed and delivered to EGS in 2017. The ICPS is a single-engine LH2/LOX system that generates 24,750 pounds of thrust. The ICPS will

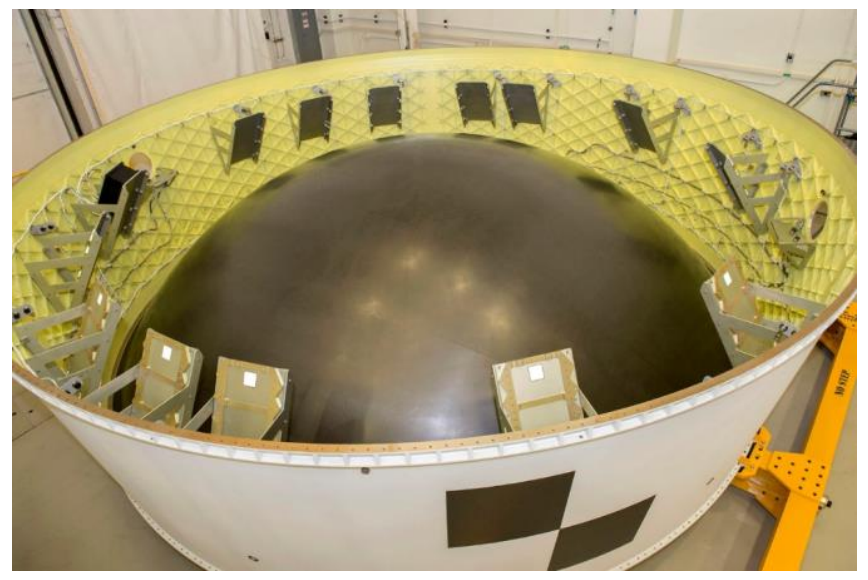

Figure 9. The completed Artemis I Orion Stage Adapter (OSA), which has volume for CubeSat payloads; brackets that hold the COTS dispensers are visible 
added and there are some minor avionics changes. For Artemis II, an emergency detection system to monitor abort conditions and communicate any abort recommendations to the Orion spacecraft will be added. For the Artemis II flight, Orion's service module will provide the TLI burn while the ICPS will perform three burns: perigee raise maneuver, apogee raise burn and disposal burn.

In the Block 1 vehicle, two adapters connect the ICPS to the core stage below it and Orion's spacecraft adapter above it. The Artemis I OSA is complete and has been delivered to EGS. For the first two Artemis flights, volume in the OSA is being used to provide rideshare opportunities for CubeSats. Thirteen $6 \mathrm{U}$ payloads are manifested for Artemis I and a limited number of $6 \mathrm{U}$ and $12 \mathrm{U}$ berths are available on the Artemis II flight. NASA selects CubeSats for ridesharing on SLS based on potential for the missions to return data that addresses lunar and Martian Strategic Knowledge Gaps (SKGs) [1]. The SLS Program provides a Secondary Payload Deployment System (SPDS) in the OSA for CubeSats. The SPDS includes mounting brackets, cable harnesses, a vibration mitigation system and an avionics unit that controls deployment. Smallsats can be deployed along the ICPS heliocentric disposal trajectory after Orion has separated safely from SLS.

The Launch Vehicle Stage Adapter (LVSA) partially encloses the ICPS and connects the core stage to the OSA. The flight unit for Artemis $\mathrm{I}$ is in final processing at Marshall Space Flight Center (MSFC) and expected to ship to KSC in 2020. For Artemis II, panels are being machined for the OSA and LVSA. ULA has started production of the Artemis II ICPS with panels for the LH2 tank being machined.

\section{Remaining Milestones}

Next year promises many exciting milestones toward integration and launch. In addition to the Green Run test series and the booster motor segments shipping to KSC, the

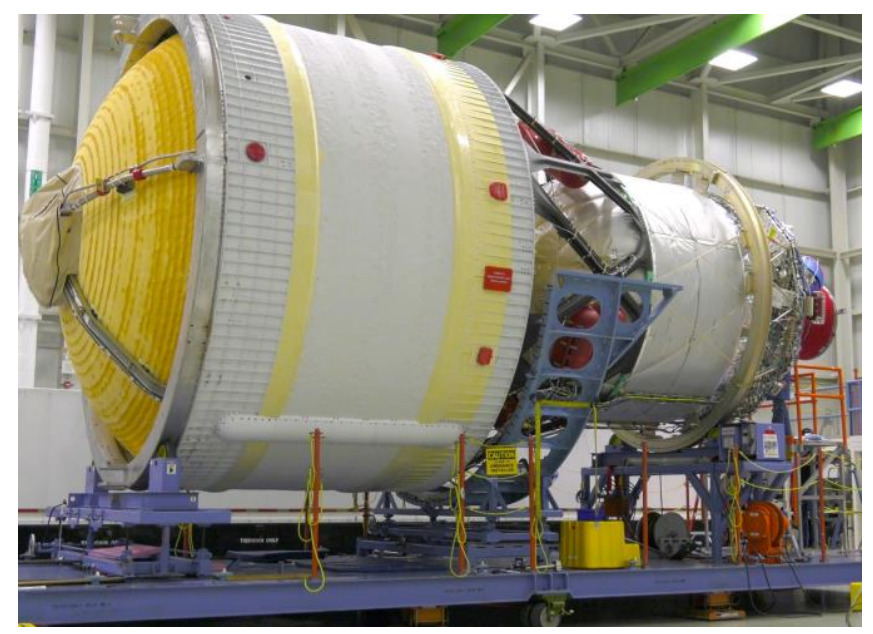

Figure 10. Completed ICPS prior to shipping to Exploration Ground Systems (EGS) at KSC

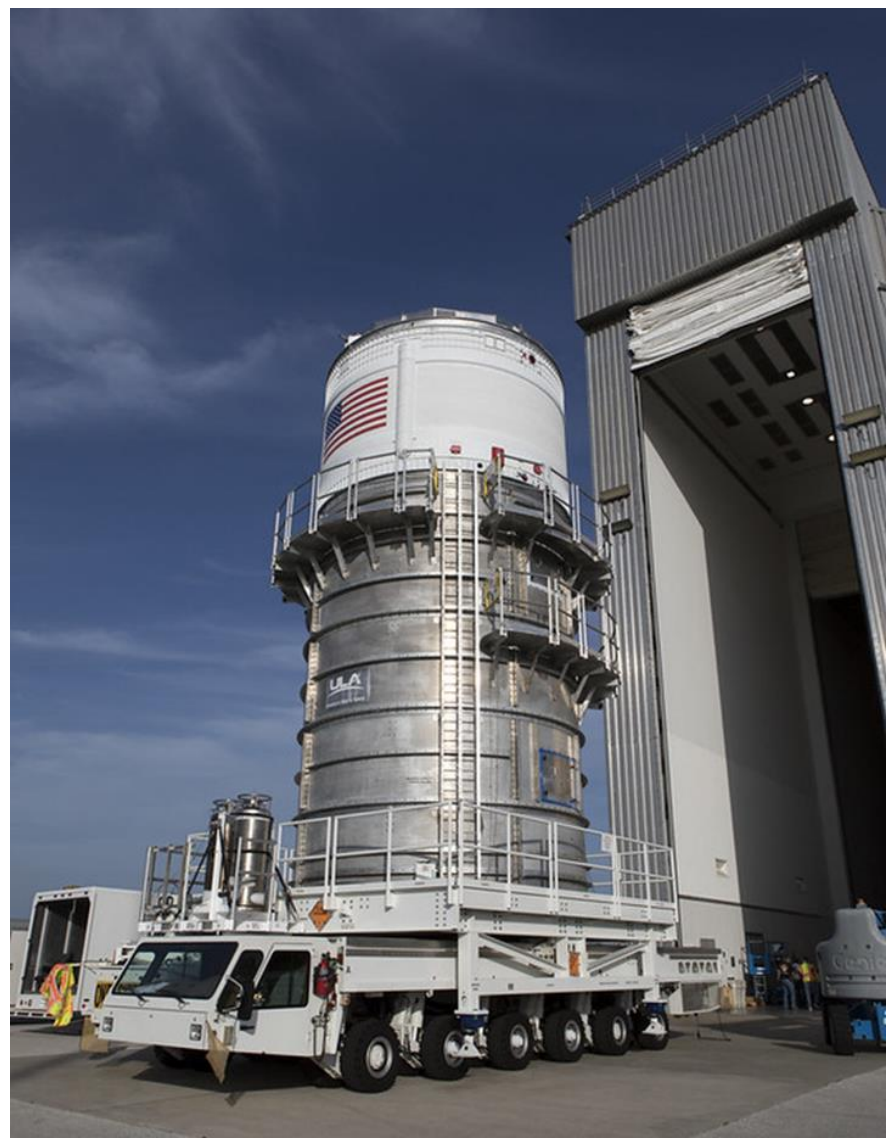

Figure 11. The Artemis I Interim Cryogenic Propulsion Stage (ICPS) is ready for stacking at KSC

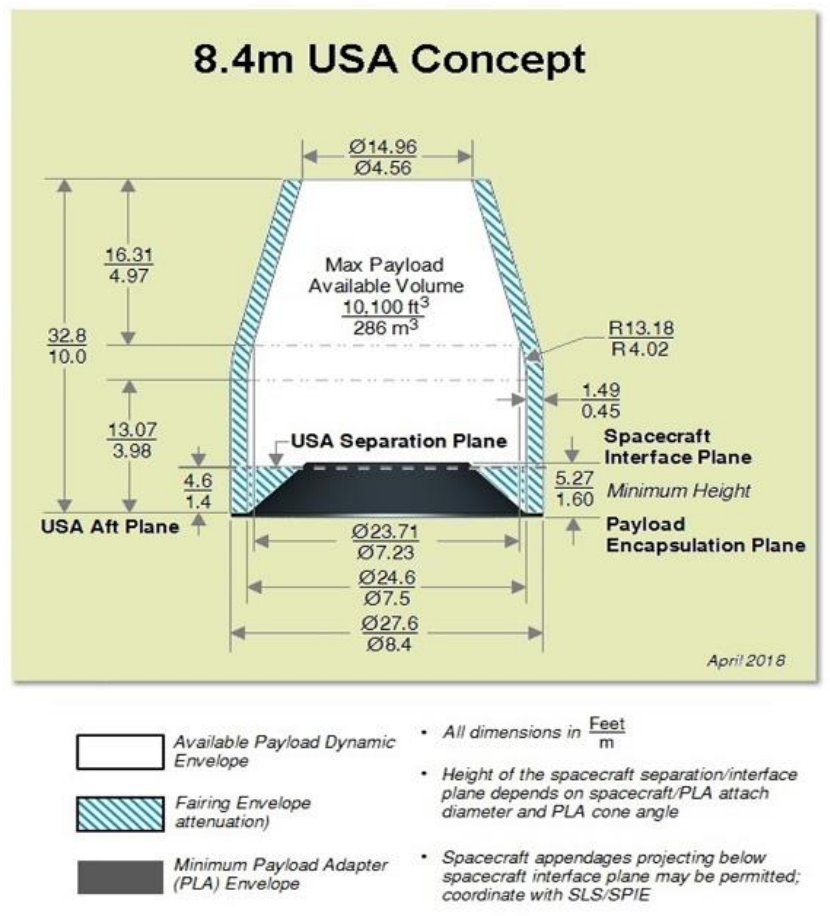

Figure 12. The Universal Stage Adapter (USA) on the Block 1B crew vehicle provides $286 \mathrm{~m}^{3}$ of volume for co-manifested payloads 


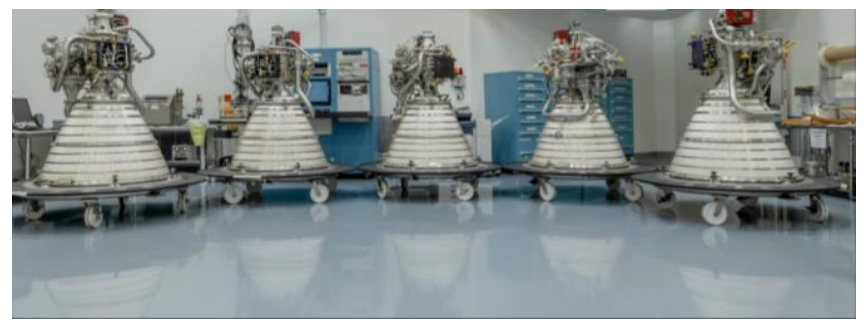

Figure 13. Completed RL10 engines for Artemis II and future flights

Program will complete its Design Certification Review (DCR) and will continue work toward Certification of Flight Readiness (CoFR). Additionally, launch monitoring facilities at KSC, MSFC and contractor locations should complete outfitting of facilities. Training and simulation activities are in progress at multiple sites and will continue until close to the time for launch.

\section{Future Capabilities}

\section{SLS Block 1 Cargo Configuration}

In addition to the Block $1 \mathrm{crew}$ vehicles designated for the initial Artemis flights, the Block 1 configuration with the

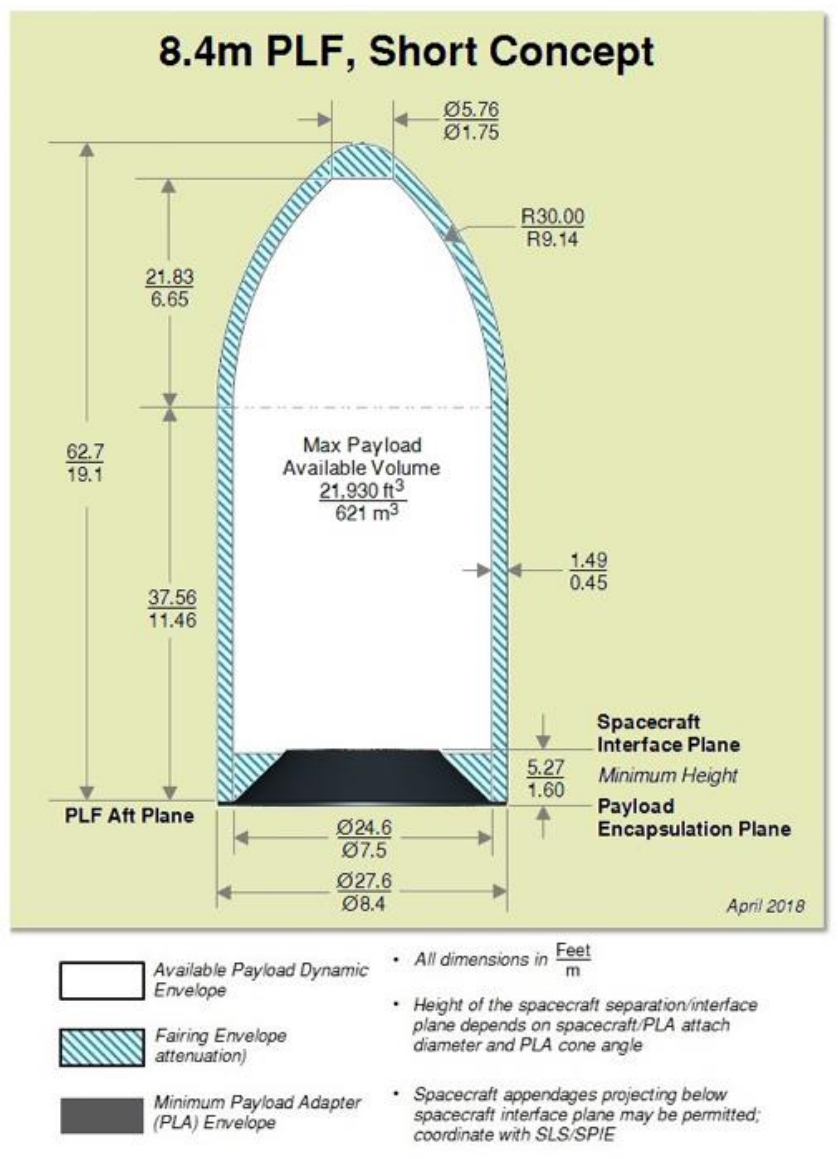

Figure 14. Conceptual diagram of $8.4 \mathrm{~m}$-diameter, $19.1 \mathrm{~m}$ long SLS fairing

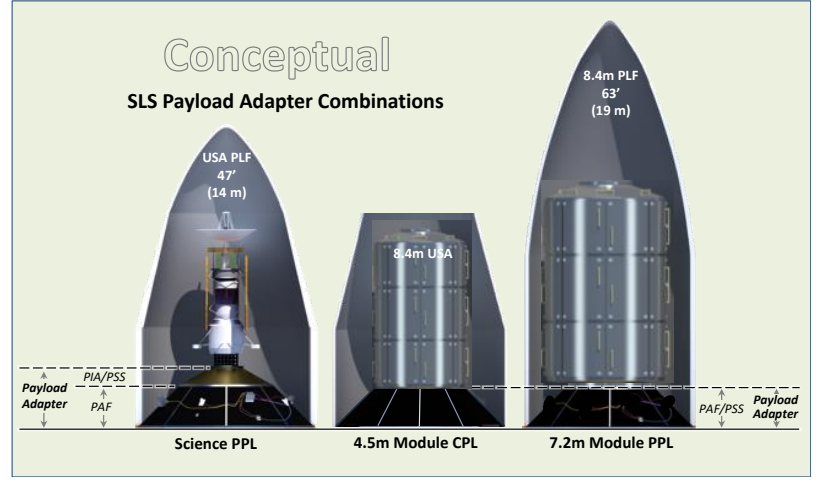

Figure 15. Sample payload configurations and payload adapters

ICPS upper stage can be outfitted with a 5 m-diameter fairing. Industry-standard payload interfaces and accommodations in the Block 1 cargo vehicle can streamline payload development. The Block 1 cargo configuration, with its high $\mathrm{C} 3$ values to the outer planets, can deliver a large useful payload mass to destinations such as Europa or Titan with reduced transit time (see Figure 17). For example, for a notional Jovian insertion mission, SLS offers a launch with $\mathrm{C} 3$ energy sufficient to eliminate the Venus-Earth-Earth gravity assist (VEEGA) trajectory that commercial vehicles require, reducing cruise time from more than six years to less than three years.

\section{SLS Block $1 B$}

SLS Block 1B uses the same core stage design as the Block 1 vehicles but replaces the single-engine ICPS with a more powerful EUS. This four-engine LH2/LOX stage together with the newly manufactured RS-25s and upgraded boosters will allow SLS to deliver between 34 to $40 \mathrm{t}$ of payload to the lunar vicinity, depending on crew or cargo configuration. The EUS, optimized for lunar trajectories, will provide both ascent/circularization and in-space transportation for payloads.

In its crew configuration, SLS Block 1B can accommodate Orion and a co-manifested payload in the USA, which provides $286 \mathrm{~m}^{3}$ of volume. The program anticipates lift capability of up to $10 \mathrm{t}$ for co-manifested payloads, which will typically separate from the EUS between five and eight hours post-launch, after reaching a safe distance from Orion.

Similar to commercial vehicles, the mechanical interface between Block 1B and a primary payload in a fairing or a co-manifested payload in the USA is a payload adapter consisting of up to three components as shown in Figure 15. Choice of a particular payload adapter depends on mission parameters. The payload adapter provides a structural and service interface to the $8.4 \mathrm{~m}$-diameter EUS forward adapter. The payload adapter can be configured with a payload interface adapter (PIA) and/or a payload separation system (PSS) to accommodate various spacecraft or payload interfaces. The PIA is an optional interface between the adapter and the spacecraft/payload that maximizes available 
volume. The PIA accommodates a PSS, which is a structural separation interface for a spacecraft or payload mounted on the adapter or PIA. Depending on the interface diameter required, it can support a variety of commercial off-the-shelf (COTS) separation systems (e.g., D1666 or 1666VS) or a new-development separation system [2].

For smallsats, rideshare opportunities for up to 21 smallsats in varying sizes may be offered on a payload adapter in the USA. Depending on the requirements of primary or comanifested payloads, deployment of larger "ring payloads," similar to those currently flown on an Evolved Expendable Launch Vehicle (EELV) Secondary Payload Adapter (ESPA) ring, might be possible. Propulsive ESPA-class capabilities are also being evaluated.

The Block 1B cargo configuration can accommodate payloads using an $8.4 \mathrm{~m}$-diameter fairing in $19.1 \mathrm{~m}$ and 27.4 $\mathrm{m}$ lengths. The $8.4 \mathrm{~m}$-diameter, $19.1 \mathrm{~m}$ shroud provides 621 $\mathrm{m}^{3}$ of volume while the $27.4 \mathrm{~m}$ fairing supplies $988 \mathrm{~m}^{3}$ of available space (see Figure 16). As with co-manifested payloads on the Block $1 \mathrm{~B}$ crew configuration, the EUS forward adapter provides an interface for various payload fairings and payload adapters.

\section{SLS Block 2}

The Block 2 crew vehicle will use evolved boosters to maximize performance, enabling SLS to place more than 45 $\mathrm{t}$ in lunar orbit. The Block 2 vehicle has the potential to carry fairings up to $10 \mathrm{~m}$ in diameter with a volume of up to $1,320 \mathrm{~m}^{3}$, several times greater than any currently available fairing, making new missions possible and simplifying spacecraft and mission design. This configuration will also take advantage of future developments in technology, while providing unique enabling capabilities for human missions to Mars.

\section{SLS FOR SCIENCE MISSIONS}

While SLS is designed to enable human exploration of the Moon as a testbed before embarking on crewed expeditions to Mars, many missions will benefit from the mass, volume and departure energy that SLS provides, including planetary science, astrophysics, heliophysics, planetary defense and commercial endeavors. Utilization of greater payload volume and mass can decrease the need for spacecraft

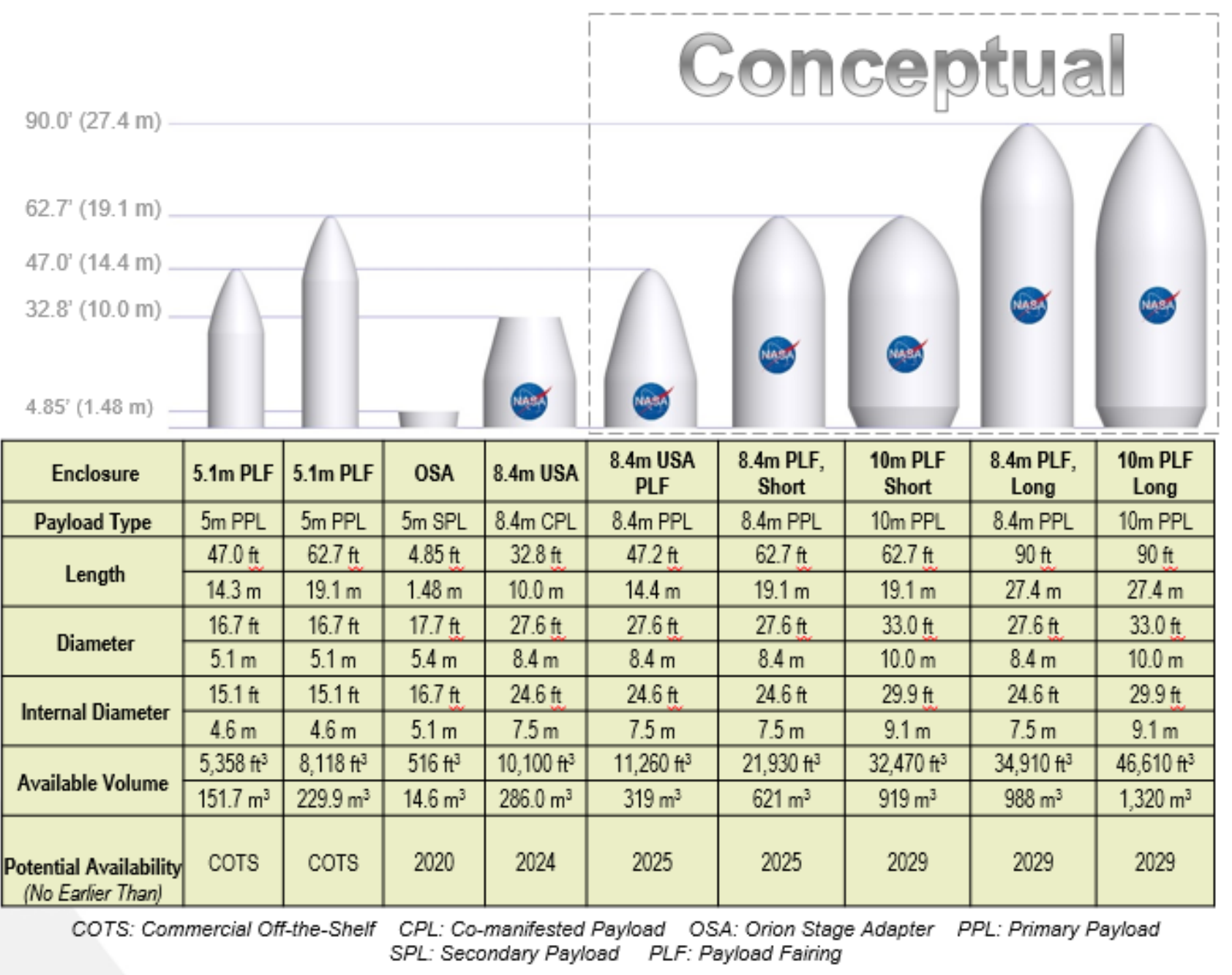

Figure 16. SLS is a flexible system, configurable with a range of fairings that provide unmatched usable volume for payloads 
miniaturization and complex deployments. Reducing cruise time with direct injection into deep space trajectories lowers operational costs, can eliminate the need to design for inner solar system conditions and increase a spacecraft's useful life. In addition, highly energetic launches that reduce outbound cruise time can allow more robust science packages and quicker data return, which can translate into programmatic benefits. An SLS Mission Planner's Guide is available in a downloadable PDF format to provide basic technical details on the system [2].

\section{Lunar and Martian Missions}

NASA's Human Exploration \& Operations Mission Directorate (HEOMD) has outlined plans for a new lunar will be available in the 2020s. The super heavy-lift capability of SLS may yield a significant mass margin that can be used to carry additional consumables or secondary payloads in $6 \mathrm{U}, 12 \mathrm{U}$ or larger sizes. With the construction of the lunar Gateway and proving out deep space technologies as an intermediate step, Mars remains NASA's horizon goal. In addition to sending astronauts to the Moon to expand knowledge of working in deep space environments, SLS may be used to launch future missions to Mars from the Gateway using a fully evolved Block 2 SLS vehicle. Large-volume habitat modules and rovers will require the large-diameter $8.4 \mathrm{~m}$ and $10 \mathrm{~m}$ cargo shrouds.

\section{Astrophysics}

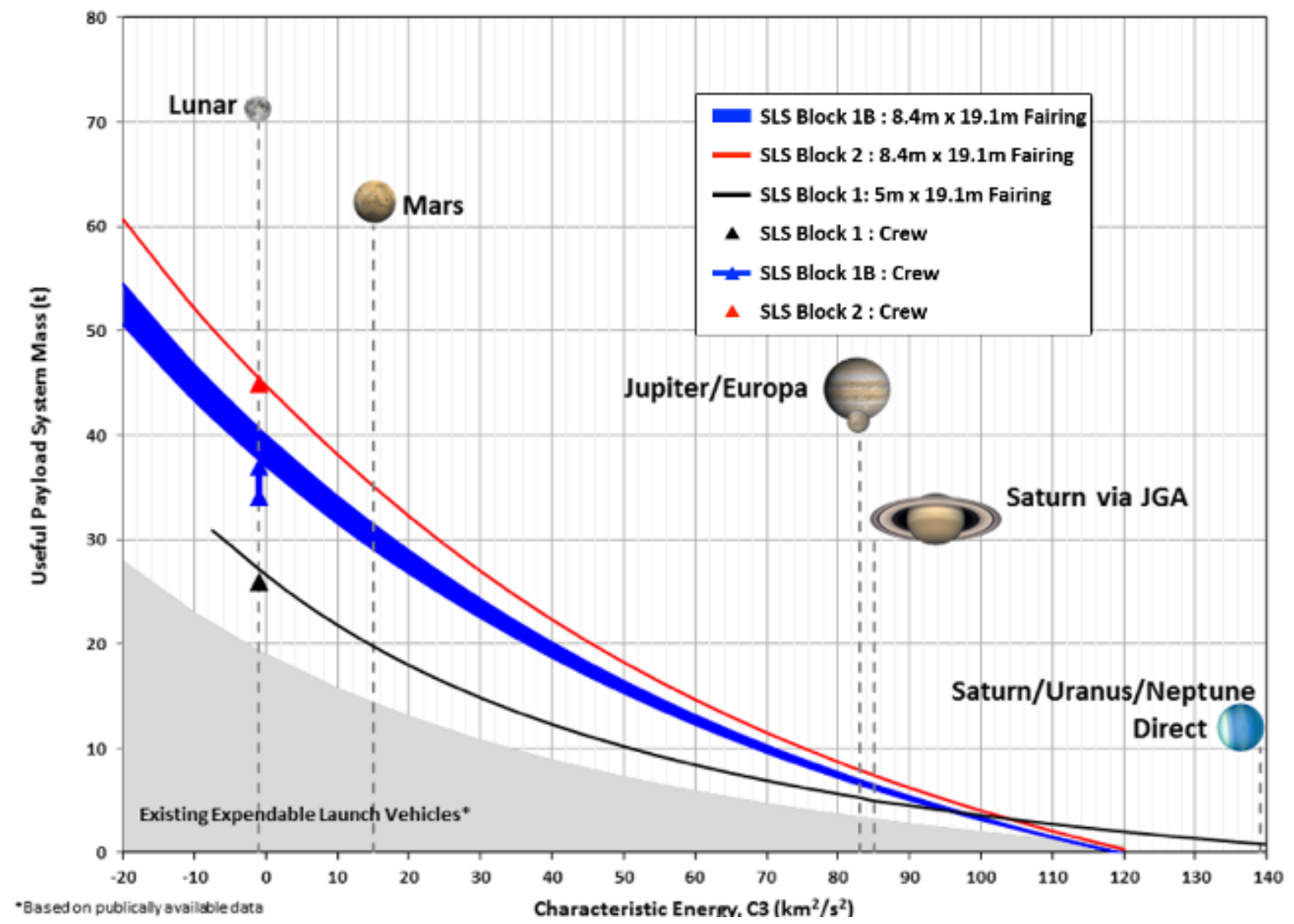

Figure 17. SLS is a unique asset for space exploration, able to deliver more mass to deep space destinations than commercial vehicles

orbiting science outpost, the Gateway, to be constructed in the 2020s. The Gateway will serve as a proving ground for technology and science missions to both better understand the Earth-Moon system and inform future missions to Mars and deeper into the solar system. The superior lift and payload volume capabilities of SLS Block 1B will enable NASA to send Orion and a co-manifested payload, such as a habitat or logistics module, to the Gateway in a single launch with Orion. For deploying more massive lunar infrastructure, Block 1B cargo flights with the $8.4 \mathrm{~m}$ fairing
Block 1B can also be used to deploy next-generation largeaperture space telescopes. After the James Webb Space Telescope (JWST) launches, the Wide Field Infrared Survey Telescope (WFIRST) is scheduled to come online. Mission planners are studying the possibility of flying WFIRST as a co-manifested payload on a Block 1B crew launch, providing cost and programmatic benefits. After WFIRST, telescopes such as the Large UV/Optical/IR Surveyor (LUVOIR) can benefit from Block 1B's capabilities. LUVOIR has a larger " $A$ " concept and a smaller "B" 
concept [3]. Mission planners are exploring using a comanifested launch for the LUVOIR B mission.

\section{Missions to the Gas Giants}

Launching the Europa Clipper probe to the Jovian system using SLS will shorten cruise time, compared to launching on a commercial rocket. SLS can directly inject the probe the heaviest science payload yet - into Jovian space, reducing transit to Europa to less than three years [4]. The shorter cruise phase means the spacecraft needs less radiation shielding and saves mass, which can translate to more mass and volume available for the science payload. Reduced outbound transit time also translates to faster data return and simpler mission design. If a follow-on Europa lander mission is launched, that mission could use the performance of SLS to send increased mass, delivering a payload in the $16 \mathrm{t}$ range using gravity assists. In addition, the earlier receipt of data from the Clipper mission can inform the lander mission, again providing potential programmatic benefits.

\section{Missions to the Ice Giants}

Looking deeper into the solar system, mission planners can harness the unique capabilities of SLS to send dual probes to Neptune and Uranus and potentially conduct flybys of their larger moons. In the next few decades, there are no trajectories that would allow a single spacecraft to fly by both Uranus and Neptune [5]. SLS can launch dual spacecraft - one to intercept Uranus and one to encounter Neptune - in a single launch. Initially both spacecraft would travel on a similar trajectory; the probes would eventually veer apart into separate trajectories [5]. A third stage and a solid-fuel motor kickstage can be included in the SLS staging architecture to enable high enough $\mathrm{C} 3$ to reach the planets (see Figure 19). The dual-spacecraft launch using SLS and a kickstage could enable reduced flight times and/or increased useful mass delivered to the planets. These options can allow additional trade-offs between cost and science and provide programmatic benefits [5].

\section{Kuiper belt and interstellar medium missions}

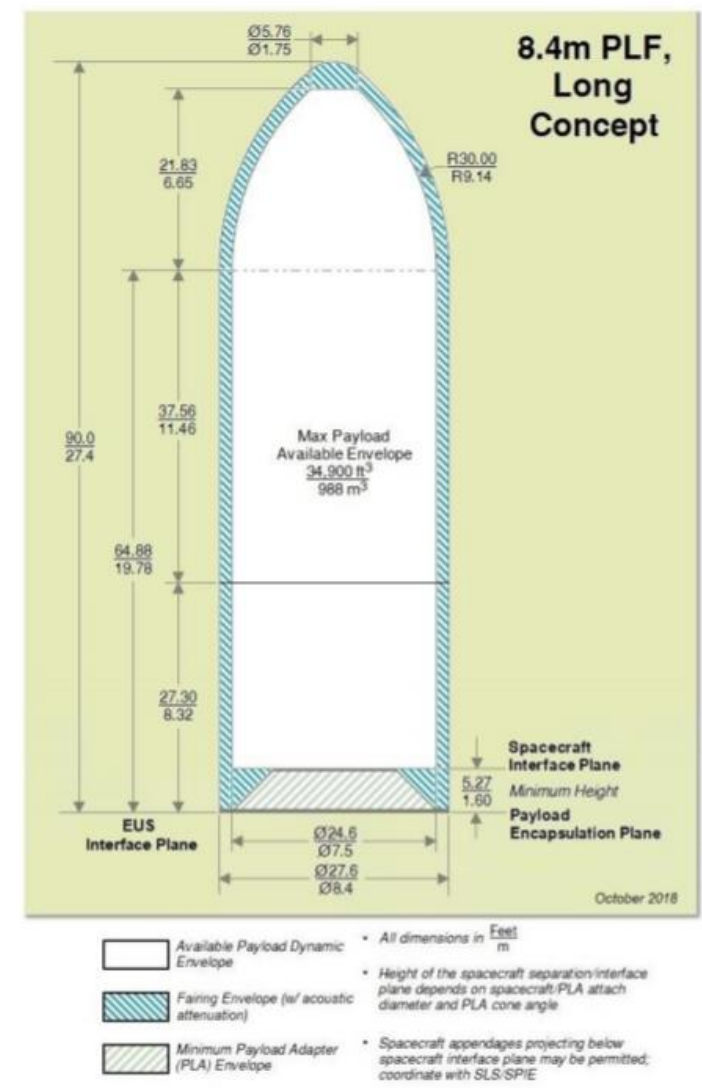

Figure 18. Concept of $8.4 \mathrm{~m}$-diameter, $27.4 \mathrm{~m}$ long fairing 


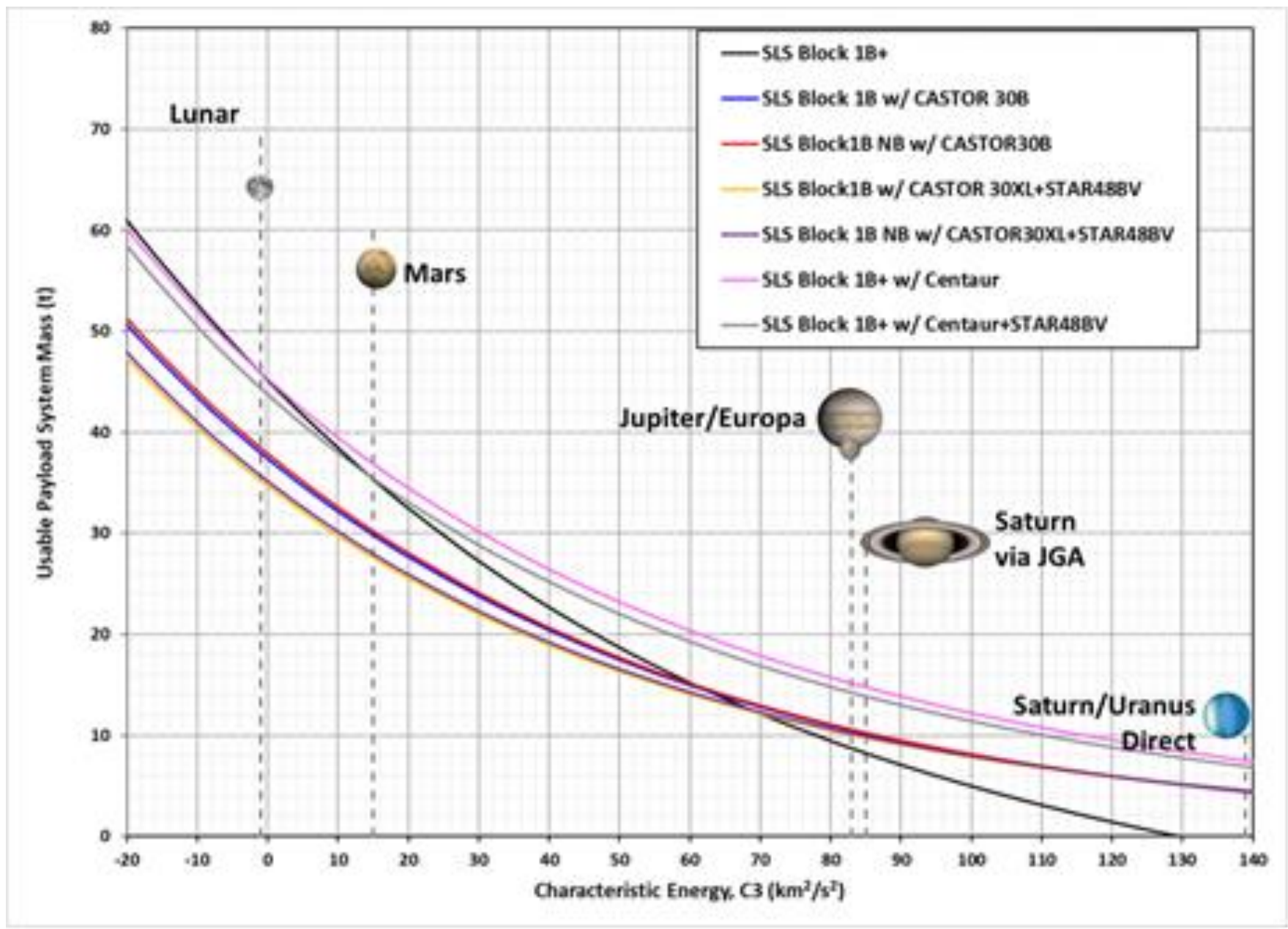

Figure 19. SLS can be configured with additional upper stages and solid motor kickstages for missions to the outer solar system

SLS could be used for a solar system escape mission with a spacecraft with mass similar to a New Horizons mission but with greatly reduced transit times. Such a mission would require an innovative trajectory design [6]. McNutt et. al. believe launch C3s in the range of $200 \mathrm{~km}^{2} / \mathrm{s}^{2}$ to $350 \mathrm{~km}^{2} / \mathrm{s}^{2}$ should be possible using SLS [6]. By using a Jupiter gravity assist, travel times of 25 to 35 years to 200 AU could be achieved. Mission concepts include investigation of the interstellar medium and its influence on the solar system, and the characterization of interstellar gas, low-energy cosmic rays, dust and magnetic fields [6].

\section{Conclusion}

With the first Block 1 crew vehicle nearing completion, a new generation of deep space exploration is dawning - the Artemis generation. SLS will give NASA the capability to send astronauts to the Moon in Orion and safely return them to Earth. This lunar exploration campaign of the 2020s, however, will be a sustained and cooperative effort among NASA and its partners to live, explore, investigate, test, demonstrate and innovate off-planet using the lunar Gateway. Technologies developed for lunar exploration will be tested with an eye toward Mars and the rest of the solar system.

With SLS, NASA has a vehicle with a clear evolutionary path to meet the nation's most demanding and exciting missions, whether that be sending a co-manifested payload of significant size and volume along with Orion to the Gateway or launching a flagship science mission as a cargo-only flight deep into the solar system. The mass, volume and departure energy of SLS provide scientists, spacecraft designers and mission planners with new and unique opportunities for astrophysics, planetary science and other ambitious missions. SLS puts once-out-of-reach missions with larger science packages or reduced cruise times now squarely with the science community's reach. 
7.

\section{REFERENCES}

[1] National Aeronautics and Space Administration, Strategic Knowledge Gaps: https://www.nasa.gov/exploration/library/skg.html

[2] Smith, David Alan, April 2018. SLS Mission Planner's Guide, Marshall Space Flight Center, Alabama, https://ntrs.nasa.gov/search.jsp?R=20170005323

[3] Buffington, Brent, Trajectory Design for the Europa Clipper Mission Concept, Jet Propulsion Laboratory, California Institute of Technology, Pasadena, California, https://trs.jpl.nasa.gov

[4] The LUVOIR Interim Report, https://asd.gsfc.nasa.gov/luvoir/resources/docs/LUVOIR_In terim_Report_Final.pdf

[5] Ice Giants Pre-Decadal Study Final Report, June 2017, https://www.lpi.usra.edu/icegiants/mission_study/Full$\underline{\text { Report.pdf }}$

[6] Paul, Michael V., McNutt, Ralph L., Jr., Vernon, Steven R., Stough, Robert W., Hitt, David, Alvarez, Erika, Enabling a Near-Term Interstellar Probe with the Space Launch System, AIAA Propulsion \& Energy Forum, Indianapolis, Indiana, 2019, 19-22 August

\section{BIOGRAPHY}

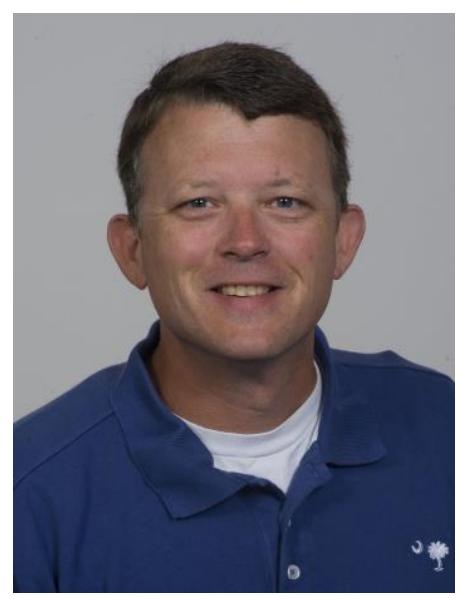

Steve Creech received a B.S. in Industrial Engineering from Mississippi State University and currently serves as the manager of the Spacecraft / Payload Integration and Evolution (SPIE) Office of the Space Launch System (SLS) Program, located at NASA's Marshall Space Flight Center in Huntsville, Alabama. In that role, he oversees development of spacecraft and payload interfaces for SLS, NASA's new launch vehicle for human and scientific exploration of deep space. Prior to serving in his current position, Creech served as deputy manager of the SPIE Office and as the SLS Program's assistant manager for strategic development, leading business development, collaboration and partnerships for future payload and capabilities. His many honors include NASA's Medal for Exceptional Service and Distinguished Performance Award and the Agency's prestigious Silver Snoopy Award. 